\title{
Cloud Radiative Forcing at Summit, Greenland
}

\author{
Nathaniel B. Miller, Matthew D. Shupe, And Christopher J. CoX \\ Cooperative Institute for Research in Environmental Science, University of Colorado, and NOAA/Earth System Research Laboratory, \\ Boulder, Colorado \\ VON P. WALDEN \\ Washington State University, Pullman, Washington
}

DAVID D. TURNER

NOAA/National Severe Storms Laboratory, Norman, Oklahoma

KONRAD STEFFEN

Swiss Federal Research Institute WSL, Birmensdorf, Switzerland

(Manuscript received 23 January 2015, in final form 11 May 2015)

\begin{abstract}
The surface energy budget plays a critical role in determining the mass balance of the Greenland Ice Sheet, which in turn has significant implications for global sea levels. Nearly three years of data (January 2011October 2013) are used to characterize the annual cycle of surface radiative fluxes and cloud radiative forcing (CRF) from the central Greenland Ice Sheet at Summit Station. The annual average CRF is $33 \mathrm{~W} \mathrm{~m}^{-2}$, representing a substantial net cloud warming of the central Greenland surface. Unlike at other Arctic sites, clouds warm the surface during the summer. The surface albedo is high at Summit throughout the year, limiting the cooling effect of the shortwave CRF and thus the total CRF is dominated by cloud longwave warming effects in all months. All monthly mean CRF values are positive (warming), as are $98.5 \%$ of 3-hourly cases. The annual cycle of CRF is largely driven by the occurrence of liquid-bearing clouds, with a minimum in spring and maximum in late summer. Optically thick liquid-bearing clouds [liquid water path (LWP) $>$ $30 \mathrm{~g} \mathrm{~m}^{-2}$ ] produce an average longwave CRF of $85 \mathrm{~W} \mathrm{~m}^{-2}$. Shortwave CRF is sensitive to solar zenith angle and LWP. When the sun is well above the horizon (solar zenith angle $<65^{\circ}$ ), a maximum cloud surface warming occurs in the presence of optically thin liquid-bearing clouds. Ice clouds occur frequently above Summit and have mean longwave CRF values ranging from 10 to $60 \mathrm{~W} \mathrm{~m}^{-2}$, dependent on cloud thickness.
\end{abstract}

\section{Introduction}

The Greenland Ice Sheet (GIS) has experienced increased surface melt extent and duration over recent decades (Mernild et al. 2011). Increases of GIS surface melt and subsequent enhanced glacial flow (Zwally et al. 2002) contribute to rising sea levels and increased freshwater flux into regional oceans. The surface energy budget modulates surface melting, and thus also the mass balance of the GIS, by controlling the surface temperature. Clouds exert a significant influence on the

Corresponding author address: Nathaniel Miller, NOAA/ESRL, 325 Broadway, Boulder, CO 80305.

E-mail: millernb@colorado.edu net radiative flux at the surface (Walsh and Chapman 1998), thereby impacting the surface energy budget.

The shortwave and longwave radiative effect of clouds, or cloud radiative forcing (CRF), can be quantified by comparing the actual surface radiative flux to the flux during an equivalent clear-sky scene. In general, Arctic clouds have a warming effect on the surface, except for a period in the summer when the sun is highest and surface albedo is lowest (Curry and Ebert 1992; Intrieri et al. 2002; Kay and L'Ecuyer 2013). However, unlike many other Arctic locations, the central Greenland surface is covered by snow throughout the year, maintaining a high surface albedo in all seasons. Snow surfaces limit the ability of clouds to reduce absorbed solar radiation because clouds cannot substantially raise 
the planetary albedo. Moreover, surface-based inversions are a common feature above ice-covered surfaces, so low-level clouds often emit at temperatures much warmer than the surface. Under these conditions, longwave radiative forcing typically dominates and clouds increase the downwelling flux compared to clear skies by $45-95 \mathrm{~W} \mathrm{~m}^{-2}$ (Shupe and Intrieri 2004; Sedlar et al. 2011; de Boer et al. 2011). Additionally, optically thin clouds can act to maximize the combined shortwave and longwave radiative effects to produce maximum warming at the surface. A notable case in central Greenland occurred when low-level liquid-bearing clouds forced the surface temperature above the melting point of snow in July 2012 (Bennartz et al. 2013).

Surface temperatures exceeding $0^{\circ} \mathrm{C}$ are rare at Summit Station $\left(72.6^{\circ} \mathrm{N}, 38.5^{\circ} \mathrm{W}\right)$, which is situated atop the GIS, approximately $3255 \mathrm{~m}$ above sea level; the most recent of these melt events occurred in 1889 and 2012 (Nghiem et al. 2012). McGrath et al. (2013) predicts the $0^{\circ} \mathrm{C}$ isotherm altitude will consistently reach Summit by the year 2025 , as estimated by surface temperature trends, suggesting more frequent future melting events at that location. Melting snow has a lower albedo than fresh snow due to changes in snow morphology and the presence of liquid water in the snowpack, providing a positive feedback by which more solar radiation is absorbed, acting to increase melting of the surface. The albedo feedback is already occurring at lower elevations and thus accelerating melting of the GIS in the ablation area (Box et al. 2012).

Changes in clouds and their properties have the potential to impart even larger impacts on the surface energy budget than changes in surface albedo, although it is unknown how a $0.09^{\circ} \mathrm{Cyr}^{-1}$ warming trend over the GIS (McGrath et al. 2013) may, in turn, modify regional clouds. Climate models are deficient in their ability to distinguish cloud phase and accurately represent cloud fraction in the Arctic, leading to large biases in the surface energy budget (Cesana et al. 2012). Consequently, CRF results are useful for discerning which improvements to modeled cloud attributes are likely to have the greatest impact for accurately representing near-surface air temperatures atop the GIS in order to accurately project future melt.

In this paper we investigate the role that clouds play in the surface energy budget over the central GIS by examining the radiative effects of clouds over Summit Station. The surface albedo is relatively stable, providing the opportunity to isolate the effect of cloud properties on the annual cycle of CRF. Surface radiative fluxes, atmospheric state profiles, and cloud property measurements are used to quantify the radiative impact of clouds from January 2011 to October 2013. In addition, time-independent relationships are developed, with applicability to other places with high year-round albedo, such as glaciers, multiyear sea ice, and regions of Antarctica. The three primary cloud property influences we explore in this study are cloud presence, liquid-water occurrence, and integrated ice-cloud thickness.

\section{Instrumentation}

A comprehensive and integrated suite of instruments, measuring the atmospheric state above Summit Station in conjunction with radiative fluxes at the surface, provides linkages between cloud properties and the surface radiation budget. For all datasets a time-averaging window of $3 \mathrm{~h}$ is used to remove the effects of inhomogeneities in the atmospheric scene while still resolving the diurnal cycle.

\section{a. ICECAPS measurements}

The Integrated Characterization of Energy, Clouds, Atmospheric State, and Precipitation at Summit (ICECAPS) project is a field campaign, in operation since May 2010, designed to characterize atmospheric properties at Summit similar to observational activities at other Arctic sites such as Barrow, Alaska (Stamnes et al. 1999), and Eureka, Canada. The instrument suite is designed to provide complementary information on atmospheric, cloud, and precipitation properties. A comprehensive description of the ICECAPS instrumentation and the retrieved atmospheric properties is outlined by Shupe et al. (2013), while pertinent details for the present study are outlined here.

A multi-instrument estimate of cloud presence (e.g., Shupe et al. 2011) includes data from a Vaisala ceilometer, a 35-GHz Millimeter Cloud Radar (MMCR), and a MicroPulse lidar (MPL). The ceilometer reports cloud-base height and occurrence but is insensitive to high-altitude clouds (above 7-8 km) and has reduced sensitivity to clouds that are predominately ice. MPL data, currently available for 2011, include backscatter information to detect cloud presence with enhanced sensitivity to ice particles, but are significantly attenuated by thick liquid layers in clouds. The MMCR is sensitive to most hydrometeors and does not attenuate significantly. With the exception of the ceilometer, these instruments are insensitive to the lowest $\approx 150 \mathrm{~m}$ and therefore may miss occurrences of fog, cloudless ice crystal precipitation (diamond dust), and blowing snow. After interpolating the available estimates of cloud presence to the same time interval ( $\approx 1 \mathrm{~min}$ ), a cloud fraction is calculated by taking the ratio of the total number of cases where cloud presence is identified by at least one instrument to the total number of data points over the 3-h window. A clear-sky 
scene is identified when the cloud fraction is below a $1 \%$ threshold. Thus, a clear scene requires persistence of clear conditions for at least $3 \mathrm{~h}$ while intermittent conditions will be classified as cloudy. The MMCR also provides vertical estimates of total cloud thickness as the sum of all range gates that have reflectivity greater than $-60 \mathrm{~dB} Z$. The integrated cloud thickness does not assume a continuous cloud layer, so the thickness of a multilayer cloud is the sum of the individual cloud thicknesses.

Temperature and moisture profiles throughout the troposphere are measured twice daily (0000 and 1200 UTC) using Vaisala RS-92 radiosondes. High-temporal-resolution temperature profiles, accurate in the lowest few kilometers of the atmosphere, are retrieved using brightness temperatures from a microwave radiometer (MWR) (Miller et al. 2013). A total of four channels from the Humidity and Temperature Profiler (HATPRO) MWR (23.84 and $31.40 \mathrm{GHz})$ and high-frequency MWR (90.0 and $150.0 \mathrm{GHz}$ ) are used to retrieve column liquid water path (LWP) and precipitable water vapor (PWV), similar to Turner et al. (2007). The two high-frequency channels increase sensitivity to baseline LWP and PWV (Crewell and Löhnert 2003), resulting in PWV and LWP uncertainties of approximately $0.3 \mathrm{~mm}$ and $3 \mathrm{~g} \mathrm{~m}^{-2}$, respectively. A conservative LWP threshold of $5 \mathrm{~g} \mathrm{~m}^{-2}$ is used to identify the presence of liquid.

Best-estimate temperature and moisture profiles, extending up to $60 \mathrm{~km}$ above the surface, are created by merging radiosonde, MWR, and the European Centre for Medium-Range Weather Forecasts (ECMWF) operational model data. Data between radiosonde profiles are linearly interpolated in time for the heights below the lowest observed altitudes. For data above this altitude and for times where the radiosonde profiles are more than $14 \mathrm{~h}$ apart, ECMWF data are blended with the existing radiosonde data such that there is a linear increase and corresponding decrease in weight, respectively. The high-temporal-resolution (at least every $40 \mathrm{~min}$ ) statistical temperature retrievals from the MWR are blended at low altitudes, such that the daily boundary layer evolution is captured below $2 \mathrm{~km}$. The radiosonde-derived moisture profiles are scaled uniformly with height so that the PWV matches the PWV derived from the MWR (Turner et al. 2003). Since low PWV values that occur at Summit can be close to, or less than, the uncertainty in the retrieval $(\approx 0.3 \mathrm{~mm})$, the profile is not scaled if the percent error of the retrieval is greater than $50 \%$. Alternatively, if the percent error is between $20 \%$ and $50 \%$ then the scaling is weighted, and a profile with a percent error below $20 \%$ is fully scaled. Finally, the merged profiles are averaged over the 3-h time window.

\section{b. Additional measurements}

The Global Monitoring Division (GMD) at the National Oceanic and Atmospheric Administration (NOAA) provides measurements of atmospheric constituents and near-surface meteorological data (available from http:// www.esrl.noaa.gov/gmd/dv/ftpdata.html). Weekly ozonesondes, launched from Summit Station, report profiles of ozone mixing ratios throughout the troposphere, extending into the stratosphere. In addition, monthly surface values of $\mathrm{CO}_{2}$ mixing ratios are provided (Dlugokencky et al. 2014). Near-surface (approximately $2 \mathrm{~m}$ and $10 \mathrm{~m}$ above the surface) meteorological data are available at one-minute resolution, including pressure, temperature, and relative humidity.

\section{c. Radiation measurements}

The net radiation at the surface $(Q)$ is a combination of four broadband radiation components:

$$
Q=\mathrm{LW} \downarrow-\mathrm{LW} \uparrow+\mathrm{SW} \downarrow-\mathrm{SW} \uparrow .
$$

Broadband radiative flux measurements, at approximately $2 \mathrm{~m}$ above the surface, are maintained by the Swiss Federal Institute of Technology (ETH) Zürich and have been operational at Summit Station in the current configuration since 2004. The upwelling and downwelling thermal emission ( $\mathrm{LW} \uparrow$ and $\mathrm{LW} \downarrow)$ are measured by a pair of Kipp and Zonen CG4 pyrgeometers, sensitive to the spectral range $4.5-40 \mu \mathrm{m}$. The upwelling and downwelling solar irradiance (SW $\uparrow$ and $\mathrm{SW} \downarrow$ ) are measured by a pair of Kipp and Zonen CM22 pyranometers, sensitive to the spectral range $200-3600 \mathrm{~nm}$. External ventilation is implemented, designed to limit riming and frosting (henceforth referred to collectively as riming), which can occur frequently at Summit Station. In addition, daily checks of the radiometer domes are performed by an on-site field technician in order to remove any ice that may exist.

During August 2013, NOAA/GMD installed a pair of Kipp and Zonen CM22 pyranometers, with the same spectral sensitivity as the ETH pyranometers, and a pair of Eppley PIR pyrgeometers, sensitive to the spectral range $3.5-50 \mu \mathrm{m}$. The shortwave measurements are aspirated with heated air and the longwave measurements are aspirated with ambient air. Daily checks for ice on the radiometer dome are performed by an on-site science technician. A dome correction factor is implemented for the longwave measurements similar to the Albrecht and Cox (1977) method, which uses the difference between the radiometer dome and case temperatures.

Figure 1 shows comparisons between ETH and NOAA LW $\uparrow$ and LW $\downarrow$ measurements for one year of 

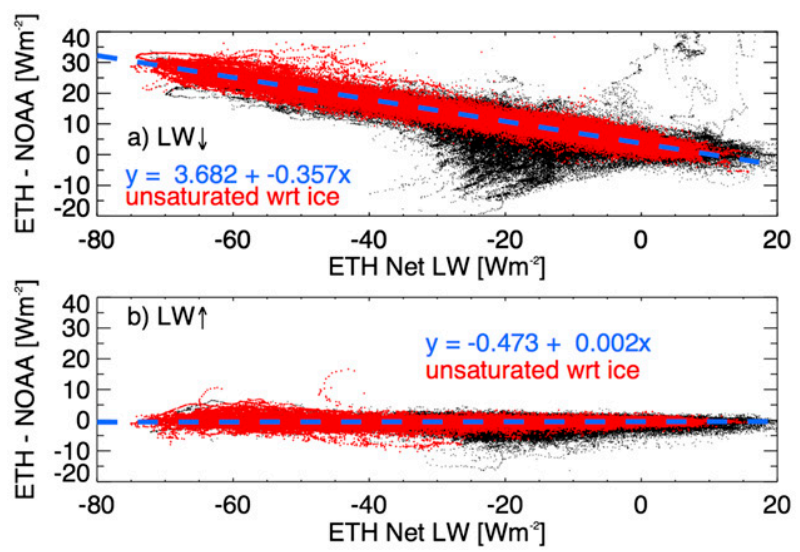

FIG. 1. Differences between ETH and NOAA/GMD measurements from September 2013 to August 2014. (a) LW $\downarrow$ and (b) $\mathrm{LW} \uparrow$ as a function of the ETH net LW (LW $\downarrow-\mathrm{LW} \uparrow)$. Periods where the 2-m air is unsaturated with respect to ice are shown in red and represent values where riming and frosting are unlikely to occur. The linear equations (blue) represent the linear least squares fit to the residuals during periods where riming and frosting are unlikely (red).

data (September 2013-August 2014). Possible rimed cases are depicted in black during times where the air at $2 \mathrm{~m}$ is saturated with respect to ice. The uncertainty in the $\mathrm{LW} \downarrow$ is $\pm 4 \mathrm{~W} \mathrm{~m}^{-2}$ with a possible negative bias of 0-6 $\mathrm{W} \mathrm{m}^{-2}$ dependent on PWV (Gröbner et al. 2014). The comparison between the ETH and NOAA measurements indicates that there is an offset in the LW $\downarrow$ measurement for clear-sky scenes, when thermal cooling of the surface is greatest. Cox et al. (2014) report a similar offset when comparing the ETH LW $\downarrow$ measurements to estimates of LW $\downarrow$ derived from the Polar Atmospheric Emitted Radiance Interferometer (PAERI) at Summit. In addition, modeled clear-sky fluxes (see section 3) are in basic agreement with the NOAA $\mathrm{LW} \downarrow$ measurements. Thus a linear fit of the $\mathrm{LW} \downarrow$ offset (ETH - NOAA) as a function of net LW is derived using measurements from periods that are likely not contaminated by rime (i.e., unsaturated with respect to ice) in order to adjust the ETH LW $\downarrow$ data for the full January 2011 to October 2013 period. Since the differences in the ETH and NOAA LW $\uparrow$ values are small (Fig. 1b), no adjustment is made to the $\mathrm{LW} \uparrow$ data.

Generally, the comparisons between the ETH and NOAA broadband SW measurements are in agreement. There is a $1.6 \mathrm{~W} \mathrm{~m}^{-2}$ difference for the $\mathrm{SW} \uparrow$ component and $-0.18 \mathrm{~W} \mathrm{~m}^{-2} \mathrm{SW} \downarrow$ difference during times when the sun is below the horizon. When the sun is above the horizon the difference of the $\mathrm{SW} \uparrow$ increases to $3.9 \mathrm{~W} \mathrm{~m}^{-2}$. This difference is within the specified error of $5 \mathrm{~W} \mathrm{~m}^{-2}$ for the CM22 pyranometers. Hence, the only adjustment to the ETH data is applied to the LW $\downarrow$ component.

\section{Calculating cloud radiative forcing}

Cloud radiative forcing is an estimation of a cloud's impact on the radiative flux at the surface. It is defined as the difference between the all-sky flux and clear-sky flux (Ramanathan et al. 1989) and is shown thus:

$$
\mathrm{CRF}=\text { Flux }_{\text {all-sky }}-\text { Flux }_{\text {clear-sky }} .
$$

CRF can be evaluated at the surface or at the top of the atmosphere. In this paper we present the surface CRF. Modeled broadband fluxes provide an estimate of the surface radiation budget under equivalent cloud-free conditions and are used to quantify the flux from atmospheric gases (i.e., the clear-sky state), which is ultimately modified by the optical and radiative properties of any hydrometeors that may be present in an overlying cloud. Hence, a best-estimate thermodynamic profile (section 2 ), which imparts its radiative signature on the ETH allsky measurements, is utilized to calculate a corresponding clear-sky flux via a radiative transfer model.

While any such forcing can elicit a response of the surface-atmospheric system over time, the focus here is on the instantaneous effects of the clouds within a given observed atmospheric profile. Alternative techniques have been used to derive CRF estimates at other Arctic sites (Dong et al. 2010), which involve an empirical curvefitting technique to estimate longwave (Long and Turner 2008) and shortwave (Long and Ackerman 2000) clearsky fluxes during cloudy scenes, using clear-sky scenes with similar environmental conditions. Because of the prevalence of surface-based inversions during clear-sky scenes (Miller et al. 2013), surface temperatures are colder during clear-sky scenes than during cloudy scenes. Hence, the cloudy-clear difference of the $\mathrm{LW} \uparrow$ component will usually be positive, manifesting as a smaller net LW CRF than calculated by the technique used in this paper. Thus, it is important to consider the technique used to calculate CRF when comparing results from different studies.

\section{Radiative transfer model}

The Rapid Radiative Transfer Model (RRTM; Clough et al. 2005) is used to estimate the clear-sky downwelling and upwelling broadband fluxes for both the SW and LW components. The water vapor continuum absorption coefficients are obtained from MT-CKD, version 2.5 (Mlawer et al. 2012).

Contributions to RRTM input profiles are obtained from atmospheric measurements, described in section 2 . The inputs include merged temperature and moisture profiles, a vertically constant $\mathrm{CO}_{2}$ mixing ratio (estimated from a monthly surface measurement), and profiles of ozone mixing ratios obtained from the most recent ozonesonde launch. Standard profiles for 


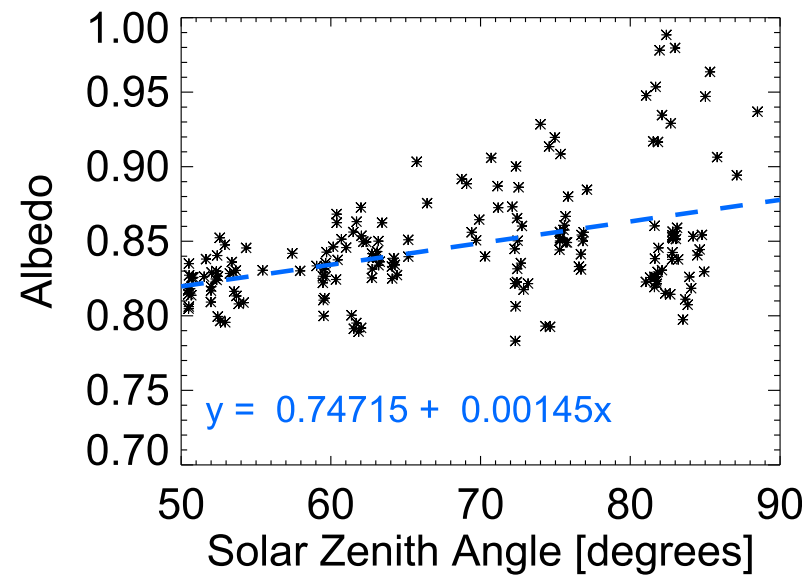

FIG. 2. Albedo as a function of solar zenith angle, derived from ETH SW measurements, during clear-sky periods. The linear least squares fit is displayed in blue.

sub-Arctic winter conditions (McClatchey et al. 1972) are used for the following atmospheric constituents: $\mathrm{N}_{2} \mathrm{O}$, $\mathrm{CO}, \mathrm{CH}_{4}$, and $\mathrm{O}_{2}$. Uncertainties in the concentrations of these four gases correspond to tenths of $\mathrm{Wm}^{-2}$ uncertainty in calculated fluxes. A constant snow emissivity of 0.985 is used for the model input, estimated from the results of Warren (1982).

The RRTM SW albedo input is estimated from ETH measurements during clear-sky periods. Since albedo is dependent on solar zenith angle (SZA) (Warren 1982), albedo in the radiative transfer model is parameterized using observations acquired during clear skies (Fig. 2). Estimating the albedo from SZA results in a better comparison of SW fluxes to measurements in clear-sky conditions than an assumed, fixed value of the albedo. Clear-sky albedo is also dependent on other factors such as snow grain size and shape. Thus, not accounting for changes in snow morphology introduces uncertainty into the modeled SW values. Approximating clear-sky albedo using the linear fit in Fig. 2 results in a root-mean-square (RMS) error of 0.076 for all clear-sky cases and a RMS error of 0.024 for cases with appreciable solar input (i.e., SZA $<80^{\circ}$ ). Despite the inherent uncertainty in representing clear-sky albedo using SZA, it is important to estimate the clear-sky albedo during a cloudy period in order to account for the cloud forcing of the broadband albedo. Bourgeois (2006) reports that for wavelengths less than $700 \mathrm{~nm}$ the albedo is greater than 0.9 and decreases with increasing wavelength. Optically thin clouds preferentially absorb shortwave radiation in the nearinfrared where the snow albedo is low, leading to an overall higher broadband albedo (Grenfell et al. 1981).

The surface (skin) temperature $\left(T_{\text {surf }}\right)$ input into RRTM is estimated from the longwave measurements using the greybody approximation with the aforementioned
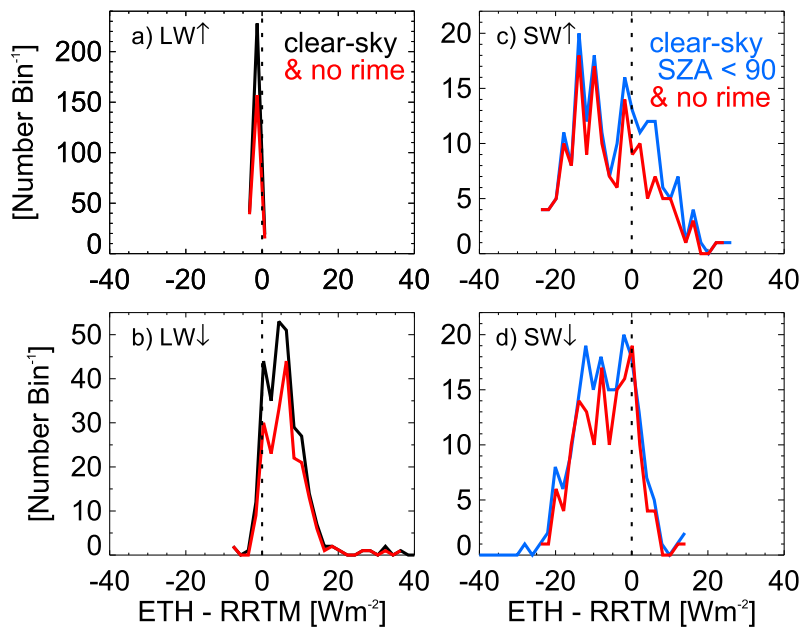

FIG. 3. Clear-sky distributions (number of occurrences per $2 \mathrm{~W} \mathrm{~m}^{-2}$ bin) of (a) LW $\uparrow$ and (b) LW $\downarrow$ residuals (ETH - RRTM). Also shown are clear-sky distributions of (c) SW $\uparrow$ and (d) SW $\downarrow$ residuals when the solar zenith angle is less than $90^{\circ}$. Clear-sky distributions for cases when rime and frost are unlikely to be present according to the science technician logbook (for the same data in black or blue) are represented in red for all panels.

surface emissivity of $0.985(\sigma=$ Stefan-Boltzmann constant):

$$
T_{\text {surf }}=\{[\mathrm{LW} \uparrow-(1-\varepsilon) \mathrm{LW} \downarrow] /(\varepsilon \sigma)\}^{0.25} .
$$

This method for estimating $T_{\text {surf }}$ is preferred in order to avoid difficulties associated with direct measurements or extrapolations from near-surface measurements. As a result, the modeled LW $\uparrow$ will be consistent with observations and is reconcilable with the definition of CRF used here because the instantaneous influence of a cloud will apply to the LW $\downarrow$ component, in contrast to the $\mathrm{LW} \uparrow$ component, which will respond over time.

\section{Evaluating CRF calculations}

The difference between modeled clear-sky fluxes and measured fluxes during clear-sky conditions provides an estimate of possible uncertainties and biases implicit in the CRF calculations. Figure 3 shows the clear-sky residuals (ETH - RRTM) for the four broadband radiation components. The red lines include only observations that are likely rime-free radiometer observations as estimated from the daily science technician log book (i.e., the radiometer dome was reported as clear between consecutive checks). This criterion may filter out some periods when the domes are clear and might miss light riming events that sublimate before the subsequent daily check. Figure 3 indicates that riming has a small effect on the clear-sky estimates. This could 
be due to the fact that low-level fog accompanies the riming events and the multisensor cloud filter would identify periods when riming occurs as cloudy. Riming does occur frequently at Summit and filtering out data during times when the logbook suggests riming might have occurred omits 2759 of 7730 total data points. Removing $35.7 \%$ of the data is a significant data loss but ensures that the CRF results are not influenced by the presence of rime. Consequently, only unrimed data are used for the subsequent analysis.

The rime-free $\mathrm{LW} \uparrow$ residuals are close to zero (median difference of $-0.4 \mathrm{~W} \mathrm{~m}^{-2}$ and interquartile range of $0.9 \mathrm{~W} \mathrm{~m}^{-2}$ ) because the longwave measurements are used to estimate the surface temperature input into RRTM. Hence, the primary difference between measured and modeled $\mathrm{LW} \uparrow$ is due to the reflected $\mathrm{LW} \downarrow$ component. The median rime-free $\mathrm{LW} \downarrow$ residual is $6.9 \mathrm{~W} \mathrm{~m}^{-2}$ with an interquartile range (IQR) of $6.2 \mathrm{~W} \mathrm{~m}^{-2}$. There are multiple potential sources of this bias. Aerosols were not included in the RRTM calculation and there could also be cases where hydrometeors overhead were not detected by the active cloud sensors; these would both contribute to the observed bias. Additionally, field-of-view considerations can contribute to the observed bias because the broadband radiometers have a hemispheric field of view as opposed to the much narrower perspective of the vertically pointing active cloud sensors. It is possible the hemispheric perspective is not completely cloud free, even though it is deemed clear overhead by the ICECAPS instrumentation during 99\% of a 3-h window (Henderson-Sellers and McGuffie 1990). In addition, uncertainties in characterizing the atmospheric state resulting from measurement uncertainties, interpolation, or approximation can contribute to both bias and spread in the residuals. The uncertainty reported by Gröbner et al. (2014) of $4 \mathrm{~W} \mathrm{~m}^{-2}$ for the $\mathrm{LW} \downarrow$ component likely increases at low temperatures and pressures (Su et al. 2008), which are common at Summit Station.

The SW $\downarrow$ clear-sky rime-free irradiance residuals (Fig. 3d) indicate a negative bias of $-5.4 \mathrm{~W} \mathrm{~m}^{-2}$ and an IQR of $11.7 \mathrm{~W} \mathrm{~m}^{-2}$. The relatively large spread in the differences (ETH - RRTM) could be attributed to reported uncertainties in broadband shortwave measurements of $1.8 \%$ (Vuilleumier et al. 2014), lingering issues in modeling SW $\downarrow$ (Kato et al. 1997), or uncertainties in characterizing the atmospheric state. Potential bias effects for clear-sky SW $\downarrow$ related to aerosols, undetected hydrometeors, and sampling field-of-view considerations all act in the opposite direction relative to the $L W \downarrow$ bias and may also be dependent on the SZA.

Clear-sky SW $\uparrow$ residuals (Fig. 3c) indicate an IQR of $15.0 \mathrm{~W} \mathrm{~m}^{-2}, 3.3 \mathrm{~W} \mathrm{~m}^{-2}$ higher than the IQR of the SW $\downarrow$.
The median rime-free $\mathrm{SW} \uparrow$ residual is also slightly larger at $-7.4 \mathrm{~W} \mathrm{~m}^{-2}$. This enhanced variability relative to $\mathrm{SW} \downarrow$ residuals is likely due to the added uncertainty of the clear-sky albedo estimates. Since some biases in $\mathrm{SW} \uparrow$ are due to biases in $\mathrm{SW} \downarrow$, these cancel when considering net SW, such that it has a much smaller net bias $\left(\approx 2.0 \mathrm{~W} \mathrm{~m}^{-2}\right)$.

While it is not clear how clear-sky uncertainties relate to all-sky uncertainties, clear-sky biases generally provide an outer bound on the biases expected for all-sky CRF calculations for each radiative component. The bias in total clear-sky CRF based on combining all radiation terms $(\mathrm{LW} \downarrow-\mathrm{LW} \uparrow+\mathrm{SW} \downarrow-\mathrm{SW} \uparrow)$ is $9.2 \mathrm{~W} \mathrm{~m}^{-2}$. The clear-sky biases in LW $\downarrow$ and SW $\downarrow$ are partially due to the lack of modeled aerosols, undetected hydrometeors, and field-of-view considerations. The influences of each of these would be smaller during cloudy scenes. For example, a partially opaque cloud below an aerosol layer would inhibit surface forcing by the overlying aerosols, limiting their contribution to the overall CRF. In addition, in all-sky conditions differences between hemispheric and narrow vertical column fields of view can lead to variability in either direction, while only leading to a bias for the "clear-sky" subset. Therefore, it is to be expected that the potential biases associated with the all-sky CRF, and its components, are substantially less than those during clear-sky scenes (i.e., $<9.2 \mathrm{~W} \mathrm{~m}^{-2}$ ).

\section{Seasonal cycle of surface flux}

The surface energy budget at Summit has been reported briefly in summer by several studies. Cullen and Steffen (2001) describe the various components of the surface energy budget at Summit for the summer of 2000 , finding that the net summer radiation is positive by an average of $14 \mathrm{~W} \mathrm{~m}^{-2}$. On average the sensible heat, latent heat, and subsurface heat fluxes are small $\left(-4,-3\right.$, and $-3 \mathrm{~W} \mathrm{~m}^{-2}$, respectively), leaving a residual of $4 \mathrm{~W} \mathrm{~m}^{-2}$ that is within the uncertainty of the measurements. Kuipers Munneke et al. (2009) reports that during the summer the primary component for surface heating is the net shortwave radiation (peaking around $120 \mathrm{~W} \mathrm{~m}^{-2}$ ), which outweighs the negative net longwave flux and turbulent fluxes. A stable boundary layer in winter, due to prevalent surface-based inversions, limits the turbulent fluxes and the surface energy budget is modulated primarily by the net longwave flux in the absence of sunlight.

Seasonal cycles of the radiative flux components as measured by the ETH radiometers are illustrated in Fig. 4a. The SW $\downarrow$ and $S W \uparrow$ values peak in June with an average net SW of about $60 \mathrm{~W} \mathrm{~m}^{-2}$. From October to 


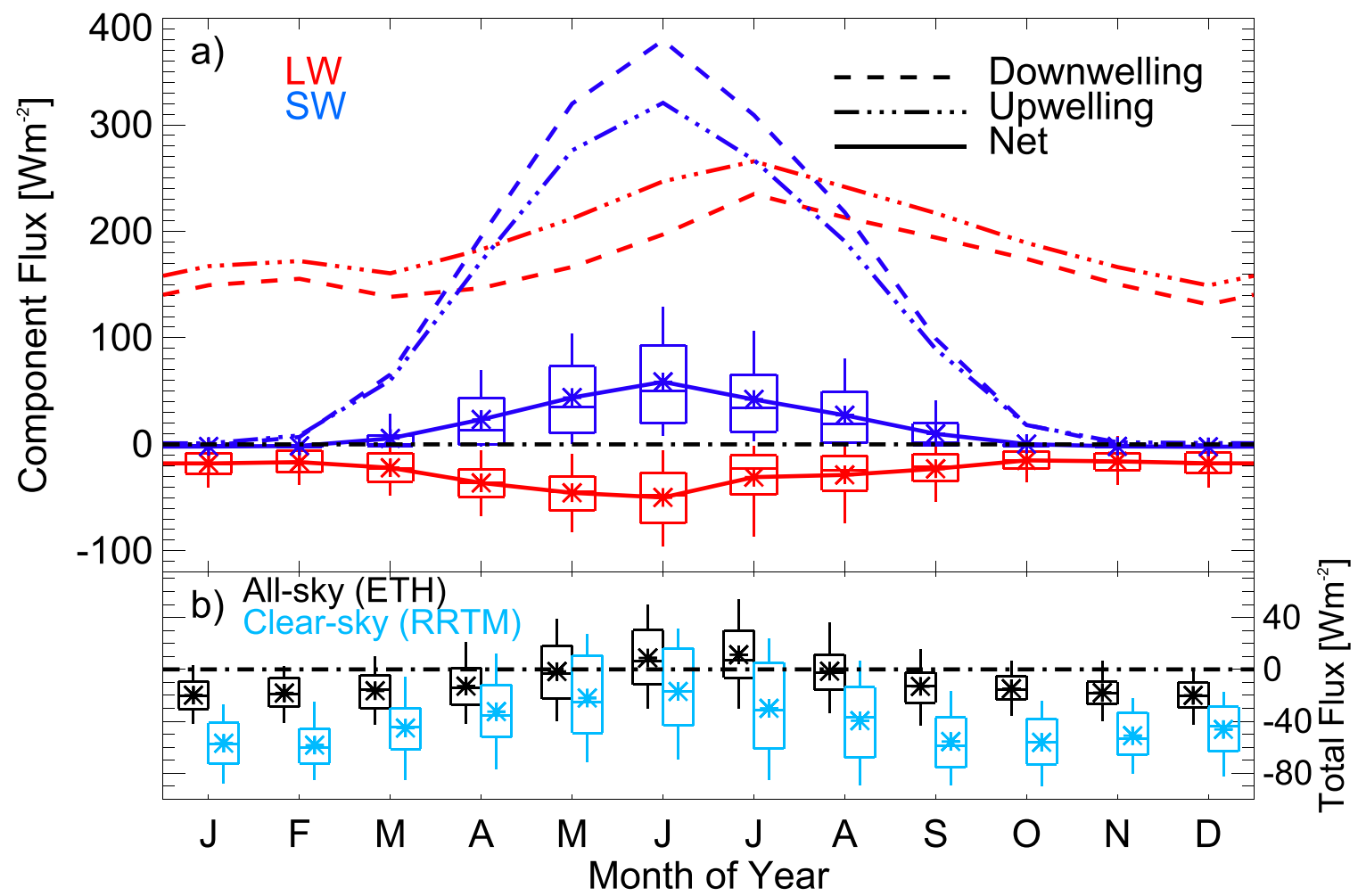

FIG. 4. (a) The annual cycle of ETH measured SW (blue) and LW (red) downwelling (dashed) and upwelling (dashed-dotted) mean monthly fluxes. The monthly net LW and SW distributions are represented by box-and-whisker plots; the box indicates the 25 th and 75 th percentiles, the whiskers indicate 5th and 95th percentiles, the middle line is the median, and the asterisk (*) indicates the mean. (b) The monthly distributions of the ETH measured (black) and RRTM modeled (light blue) total flux.

February the net SW radiation is negligible. Counteracting this solar heating, the surface cools in the LW by emitting more LW radiation than is received from the overlying atmosphere. The surface emits the greatest amount of longwave radiation, and receives the greatest amounts of LW $\downarrow$, during July when the maximum surface temperatures occur (Shupe et al. 2013). The difference between $\mathrm{LW} \uparrow$ and $\mathrm{LW} \downarrow$ is greatest in the late spring and early summer, suggesting that the increase in surface temperatures is not driven by the LW $\downarrow$ but rather by the increase in $S W \downarrow$. The net radiation is fairly stable $\left(\approx-20 \mathrm{~W} \mathrm{~m}^{-2}\right)$ from autumn to spring, while the net radiative flux is positive for the majority of the time from May to August (Fig. 4b).

Variability of net LW and SW is mainly due to the diurnal and seasonal cycles of incident solar radiation. The diurnal cycle is largest in June when the solar influence peaks midday and the surface radiatively cools when the sun approaches the horizon near midnight. The mean net SW flux in July is slightly lower than in May, but what is more striking is the asymmetry in the net LW values between May and July. When the net radiation is considered (Fig. 4b), July is similar to June. Comparatively, the net clear-sky flux, as modeled using
RRTM, shows a decrease from June to July. Generally, clear-sky estimates are lower than the measured values indicating that clouds warm the surface relative to clear skies in all months, as will be discussed in section 6 .

\section{Cloud radiative forcing}

The effect of clouds on the annual cycle of surface radiative fluxes is examined via the CRF (Fig. 5). The SW $\downarrow$ $\mathrm{CRF}$ is negative because clouds reflect incoming solar radiation, leading to cooling at the surface. Interestingly, the greatest SW $\downarrow \mathrm{CRF}$ and $\mathrm{SW} \uparrow \mathrm{CRF}$ occur in July, whereas the peak in SW $\downarrow$ occurs in June (Fig. 4a). The small magnitude of net SW CRF indicates that even in the summer the SW CRF is limited because of consistently high surface albedo values. The SW cooling effect peaks in July, with an average of $-18 \mathrm{~W} \mathrm{~m}^{-2}$ and the 5 th percentile approaching $-55 \mathrm{~W} \mathrm{~m}^{-2}$. The higher variability of net SW CRF in summer months is attributed to the diurnal cycle of incoming solar radiation (i.e., variability of SZA over the diurnal cycle), variability of cloud properties, and uncertainty in the clear-sky albedo estimates.

Since the instantaneous CRF of $\mathrm{LW} \uparrow$ is negligible, the net LW CRF is driven by the LW $\downarrow$ forcing (Fig. 5b). 


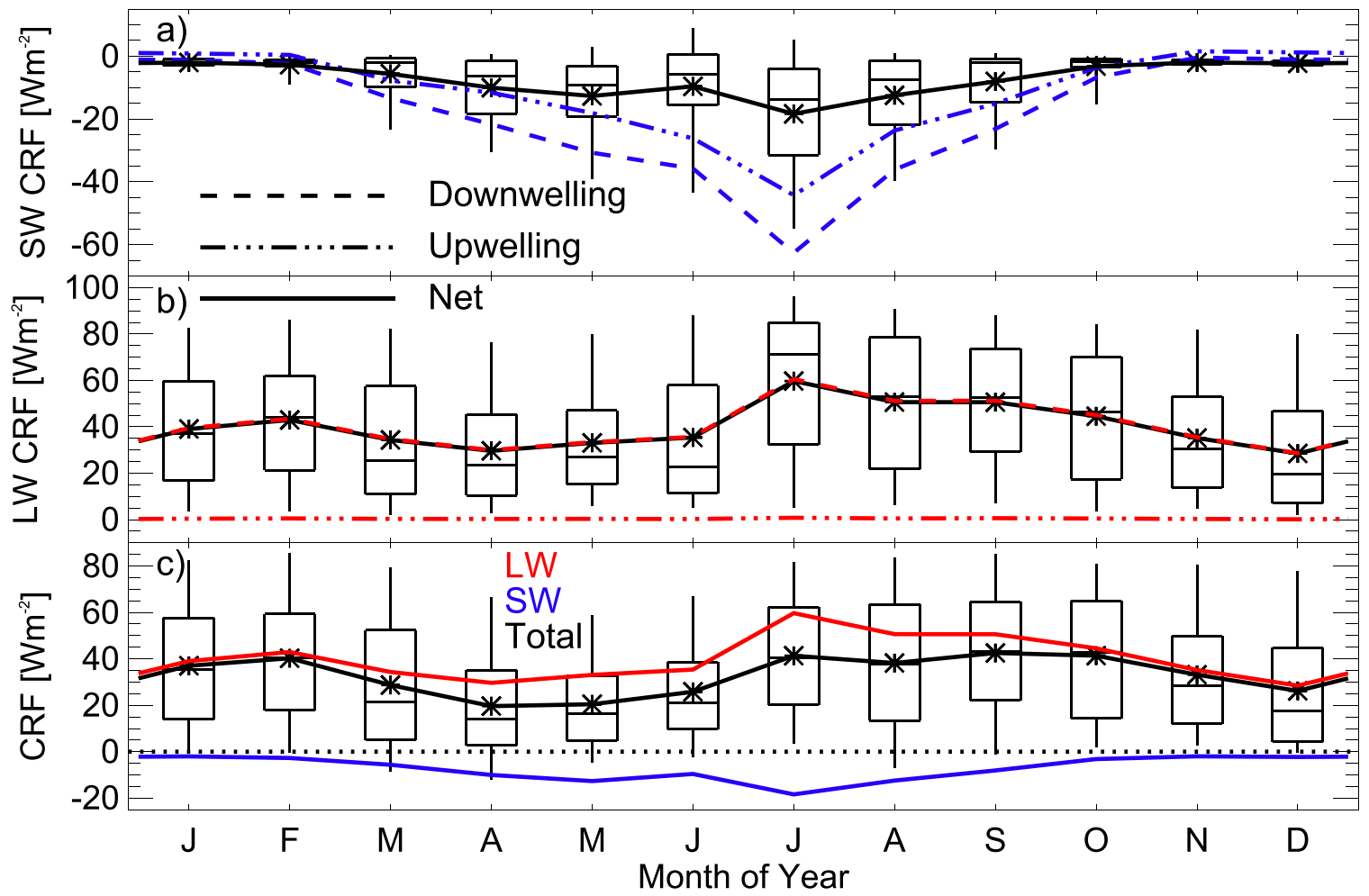

FIG. 5. (a) Monthly mean SW $\downarrow$ (dashed), SW $\uparrow$ (dashed-dotted), and net (solid) CRF and (b) the equivalent LW CRF components. (c) The monthly mean LW (red), SW (blue), and total (black) CRF. Distributions of net SW CRF, net LW CRF, and total CRF in (a)-(c) are represented by box-and-whisker plots. The box indicates the 25 th and 75 th percentiles, the whiskers 5 th and 95 th percentiles, the horizontal line inside the box is the median, and the asterisk $(*)$ indicates the mean.

Positive net LW CRF occurs year round as clouds warm the surface by insulating the surface, effectively reducing its cooling rate compared to clear skies. Similar to the SW CRF, there is an increase in the magnitude of net LW forcing from June to July. The average net LW CRF decreases from July $\left(60 \mathrm{~W} \mathrm{~m}^{-2}\right)$ to the end of the year $\left(\right.$ December $\left.=29 \mathrm{~W} \mathrm{~m}^{-2}\right)$, with a slight rebound in winter and a second minimum in April $\left(30 \mathrm{~W} \mathrm{~m}^{-2}\right)$.

On average, the total CRF (Fig. 5c), which combines LW and SW effects, is positive for all months of the year with an annual average value of $33 \mathrm{~W} \mathrm{~m}^{-2}$. Including possibly rimed data decreases the annual average by $3.6 \mathrm{~W} \mathrm{~m}^{-2}$, with minimal seasonal influence. However, it is unclear if this decrease is due to eliminating periods with rime, which are often clear-sky, or to measurement bias caused by the rime itself.

The emergence of negative SW CRF in the spring, combined with a relatively low LW CRF, leads to a spring minimum of the total CRF. During the study period (January 2011-October 2013) there are 4971 unrimed 3-h averaged data points and only $1.5 \%$ of the total CRF values are negative. A substantial surface warming, due to clouds, occurs in July associated with a sharp increase in the net LW CRF, which overwhelms the cooling effect of the corresponding increase in SW CRF magnitude. The large CRF in July is a departure from results reported for other Arctic locations, which have a period in the summer where the average total CRF is negative (Intrieri et al. 2002; Shupe and Intrieri 2004; Dong et al. 2010; Kay and L'Ecuyer 2013). The year round snow cover at Summit limits the amount of shortwave radiation absorbed by the surface, tempering the ability of the clouds to reduce the net shortwave radiation, such that the total CRF is dominated by cloud longwave radiation warming effects in all months. The diminishing influence of the SW component from summer into fall, coupled with the slowly decreasing LW $\mathrm{CRF}$, results in a relatively constant total CRF from July to October.

Since the annual cycle of the total CRF is primarily influenced by changes in the cloud properties and not large changes in albedo, the following subsections investigate the annual cycle of specific cloud properties and characterize their impact on the surface radiation.

\section{a. Cloud fraction}

Cloud presence is a first-order control that clouds have on the surface. Figure 6 a depicts the annual cycle of 


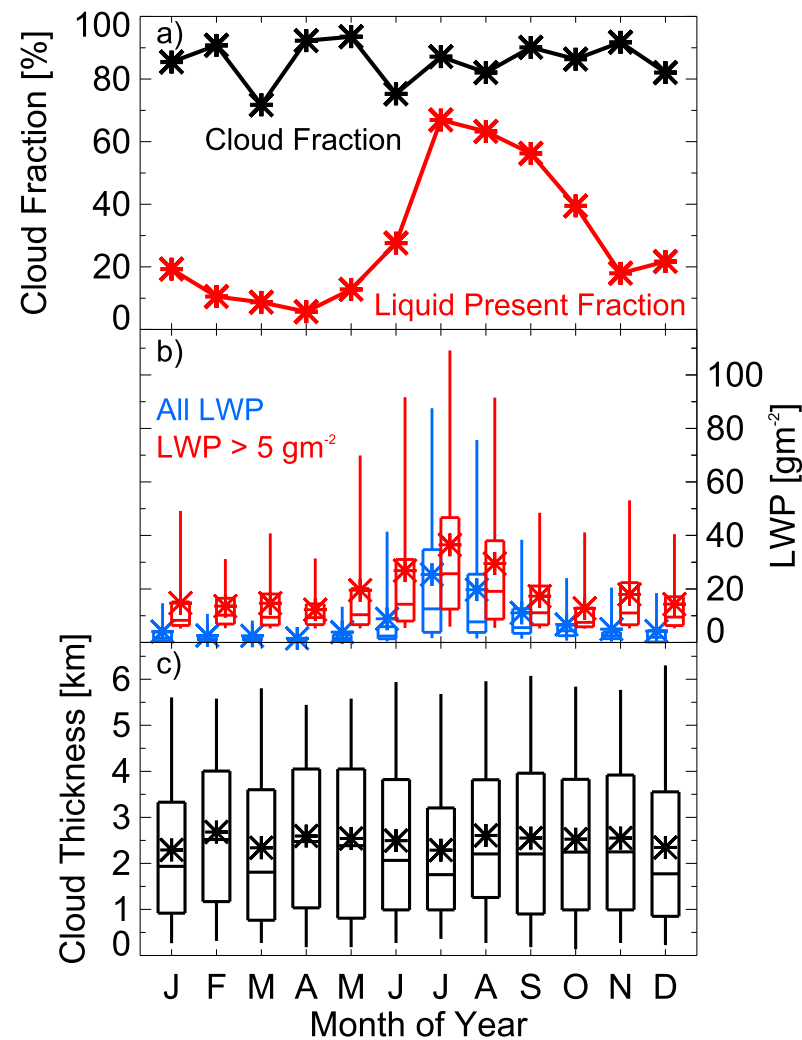

FIG. 6. (a) Monthly total cloud occurrence fraction (black) and fractional occurrence of liquid-bearing clouds (LWP $>5 \mathrm{~g} \mathrm{~m}^{-2}$, red). (b) Monthly distributions of LWP for all cases (blue) and liquid-bearing clouds (red). (c) Monthly distributions of vertically integrated cloud thickness when clouds are present. The box indicates the 25th and 75th percentiles, the whiskers 5th and 95th percentiles, the horizontal line inside the box is the median and the asterisk (*) indicates the mean.

cloud fraction using multisensor observations from January 2011 to October 2013. The overall cloud fraction for the study period is $86 \%$ with lower values in March $(72 \%)$ and June $(75 \%)$. The fact that cloud fraction does not exhibit an annual cycle suggests that it is not the primary driver in defining the annual cycle of total CRF.

Figure 7 shows that when the cloud fraction (based on 3-h averages) is between $80 \%$ and $90 \%$, the mean LW $\mathrm{CRF}$ is about $20 \mathrm{~W} \mathrm{~m}^{-2}$, and is greater than $25 \mathrm{Wm}^{-2}$ when the cloud fraction is more than $90 \%$. A majority of monthly averages have cloud fractions near $90 \%$, accounting for monthly LW CRF averages of $20-30 \mathrm{~W} \mathrm{~m}^{-2}$ for most of the year. Over the western Arctic, Dong et al. (2010) and Shupe and Intrieri (2004) find a similar relationship between LW CRF and cloud fraction, but with higher mean LW CRF $\left(55 \mathrm{~W} \mathrm{~m}^{-2}\right)$ for large cloud fractions. The smaller mean value found here is likely due to locational differences in cloud and environmental properties, but may also be influenced by a different

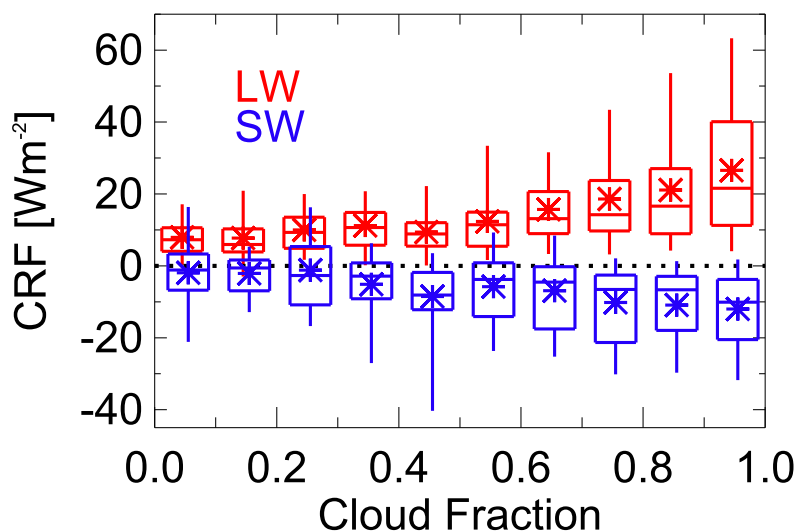

FIG. 7. Statistics of LW CRF (red) and SW CRF (blue) as a function of cloud fraction over a 3-h window. The SW data are for SZA $<90^{\circ}$. The box indicates the 25 th and 75 th percentiles, the whiskers 5 th and 95 th percentiles, the horizontal line inside the box is the median, and the asterisk (*) indicates the mean.

time-averaging window. The mean SW CRF is about $-10 \mathrm{~W} \mathrm{~m}^{-2}$ for cloud fractions between $80 \%$ and $100 \%$ (Fig. 7), offsetting less than half of the LW component. LW and SW CRF variability at the lower cloud fractions are partially due to clear-sky model errors discussed in section 4, such as differences in field of view and uncertainty in the albedo estimates. The larger variability for the highest cloud fractions is due to variability in cloud microphysics and other environmental properties such as SZA.

\section{b. Presence of liquid water}

Cloud phase is important because the optical properties of liquid-bearing clouds differ from those of iceonly clouds. A significant increase in PWV and LWP occurs in July at Summit (Shupe et al. 2013; Miller et al. 2013). An increase in water vapor decreases the transmissivity in the $18-35-\mu \mathrm{m}$ window and thus the atmosphere emits more downwelling radiation (Turner and Mlawer 2010). Yet, the effect of PWV on LW $\downarrow$ is small compared to the effect of a coordinated increase in LWP. The occurrence of liquid-bearing clouds at Summit peaks in July (67\%), with similarly elevated values in August and September (Fig. 6a). The largest monthto-month increase in liquid-bearing clouds is for the transition from June to July $(+39 \%)$, associated with a smaller increase in overall cloud fraction $(+12 \%)$.

In July and August, not only are there more liquidbearing clouds, but the clouds contain more condensed liquid compared to the rest of the year (Fig. 6b). In July, when liquid water is present, the average amount throughout the entire atmospheric column is $36 \mathrm{~g} \mathrm{~m}^{-2}$. June and August have similar LWP distributions when liquid clouds are present, but the overall liquid-bearing 


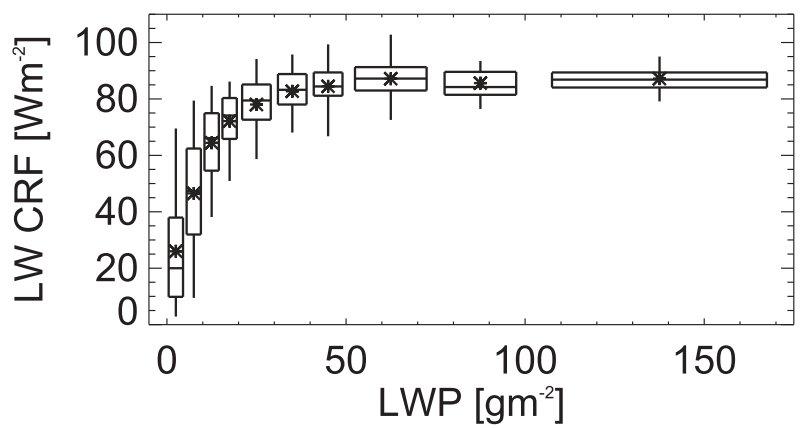

FIG. 8. Statistics of LW CRF as a function of LWP over a 3-h window. The box indicates the 25 th and 75 th percentiles, the whiskers 5 th and 95 th percentiles, the horizontal line inside the box is the median, and the asterisk (*) indicates the mean.

cloud fraction is much lower in June. April has the lowest liquid-bearing cloud fraction $(6 \%)$ and the least amount of supercooled water present in these clouds $\left(12 \mathrm{~g} \mathrm{~m}^{-2}\right.$, on average). In general, the annual LW CRF cycle (Fig. 5) follows the annual cycle of liquid-bearing cloud occurrence (Fig. 6a), with a maximum in July and a minimum in April, suggesting the importance of these clouds on the total CRF.

Cloud optical depth is a key factor in determining cloud transmissivity. Using LW optical depth approximations given by Bennartz et al. (2013), it is estimated that the transmission for a cloud with LWP $=20 \mathrm{~g} \mathrm{~m}^{-2}$ is less than $10 \%$. When considering a cloud containing $30 \mathrm{~g} \mathrm{~m}^{-2}$ of liquid water, the transmission drops to $3 \%$, effectively creating an opaque layer overlying the surface with an emissivity $(\varepsilon=1-t)$ close to 1 (Curry and Herman 1985). Figure 8 shows a nonlinear increase in LW CRF as LWP increases from 0 to $30 \mathrm{~g} \mathrm{~m}^{-2}$. Above LWP $=$ $30 \mathrm{~g} \mathrm{~m}^{-2}$ the LW CRF asymptotes to a mean value of approximately $85 \mathrm{~W} \mathrm{~m}^{-2}$. This LW saturation effect has been observed in other studies, although the specific asymptote value varies and is dependent on such factors as cloud height, temperature, and hydrometeor size (Shupe and Intrieri 2004). Results near Svalbard indicate that LW CRF asymptotes to approximately $75 \mathrm{~W} \mathrm{~m}^{-2}$ (Sedlar et al. 2011), while values in the Beaufort Sea asymptote to $65 \mathrm{~W} \mathrm{~m}^{-2}$ (Shupe and Intrieri 2004). Inexplicably, at Barrow, Alaska, Dong et al. (2010) show a linear increase in LW CRF (up to $\approx 70 \mathrm{~W} \mathrm{~m}^{-2}$ ) with an increase in LWP (up to $\approx 150 \mathrm{~g} \mathrm{~m}^{-2}$ ) and no saturation effect.

SW CRF is not only a function of LWP but also a function of SZA (Fig. 9a). The dependence of SW CRF on SZA has been demonstrated above sea ice by Fitzpatrick and Warren (2005) and Shupe and Intrieri (2004). Large SZA corresponds to small SW $\downarrow$ flux and thus a lower overall SW CRF potential, and vice versa. For SZA $<65^{\circ}$ an increase in LWP leads to an increase in the magnitude of SW CRF. Mean SW CRF values below $-60 \mathrm{~W} \mathrm{~m}^{-2}$ can occur for cases of low SZA and large amounts of liquid water. For SZA $>65^{\circ}$ the SW CRF sensitivity to LWP is limited to a much smaller range (LWP $<20 \mathrm{~g} \mathrm{~m}^{-2}$ ).

SW CRF, unlike LW CRF, remains sensitive to variations in LWP greater than $30 \mathrm{~g} \mathrm{~m}^{-2}$ for relatively low SZA (Fig. 9a). The SW optical depth, affecting the direct transmission, is approximately double that of the LW optical depth (Petty 2006, 196-198). Even though the direct transmittance of an optically thin (LWP $=10$ $40 \mathrm{~g} \mathrm{~m}^{-2}$ ) liquid-bearing cloud is lower for shorter wavelengths, the overall transmittance is higher due to the forward scattering of SW radiation. Forward scattering is more pronounced at a lower SZA. In addition, a photon with a high incidence angle will travel through a longer path length through the atmosphere and have a greater chance of being absorbed before reaching the surface. Hence, the decreased sensitivity of SW CRF to changes in LWP at high SZA is likely due to a decrease in the diffuse component of SW $\downarrow$.

Figure $9 \mathrm{~b}$ depicts mean total radiative forcing that liquid-bearing clouds impart on the surface as a function of SZA. Since the maximum SW cooling of $-65 \mathrm{~W} \mathrm{~m}^{-2}$ (Fig. 9a) is smaller in magnitude than the more prevalent maximum warming of $85 \mathrm{~W} \mathrm{~m}^{-2}$ (Fig. 8), clouds warm the surface under all conditions. For times when the sun is close to the horizon (high SZA), the total CRF is dominated by LW effects. However, when the sun is higher in the sky, SW cooling effects become somewhat more important at the highest observed LWPs. At these times, optically thin clouds provide the maximum warming of the surface. The specific LWP value that produces the maximum CRF appears to be larger at higher SZA. The 11 July 2012 Summit case study investigated by Bennartz et al. (2013) reports that without a LWP between 10 and $40 \mathrm{~g} \mathrm{~m}^{-2}$ surface temperatures would not have exceeded the melting point of snow, even during times of peak insolation. Hence, thin liquid-bearing clouds are a significant factor in warming the surface during the summer months.

\section{c. Ice phase clouds}

In addition to cloud presence and phase, the vertically integrated cloud depth can be an important factor in determining its overall optical depth and consequently the radiative forcing at the surface. There is no clear seasonal cycle in the integrated cloud thickness (Fig. 6c); the average cloud thickness for all months is between 2 and $3 \mathrm{~km}$, suggesting that cloud thickness is of secondary importance relative to cloud phase.

Figure 8 shows that for small LWP values, the LW CRF varies significantly, ranging from nearly 0 to $70 \mathrm{~W} \mathrm{~m}^{-2}$ for 

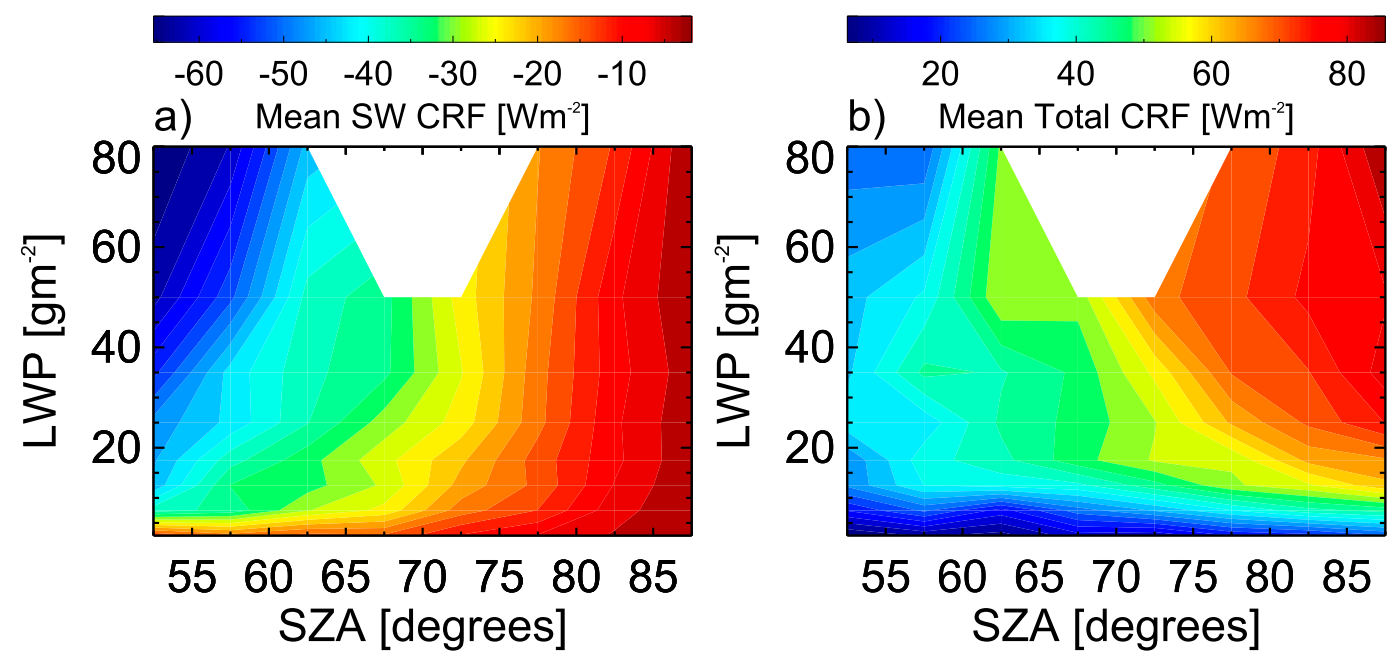

FIG. 9. (a) Mean SW CRF and (b) mean total CRF, binned according to solar zenith angle and LWP, for the time period spanning January 2011-October 2013.

clouds with $\mathrm{LWP}<5 \mathrm{~g} \mathrm{~m}^{-2}$. Cases with $\mathrm{LWP}<5 \mathrm{~g} \mathrm{~m}^{-2}$ (i.e., those with little or no liquid) are investigated further in order to characterize the influence of cloud thickness on CRF for clouds composed predominantly of ice.

For mixed-phase clouds, de Boer et al. (2011) indicate that CRF is sensitive to the optical depth for ice, which is dependent on the ice water path. The primary determinant of the optical depth of an ice-phase cloud is the area and number concentration of ice crystals (Curry et al. 1990). Cloud thickness is used as a proxy here for the total amount of ice in the column even though the number concentration and hydrometeor size can vary for each atmospheric layer. Figure 10 depicts a linear relationship of LW CRF as a function of the integrated depth of the ice cloud. The variability in each $0.5-\mathrm{km}$ bin is likely due to the aforementioned properties of the ice crystals, while the increase in LW CRF is due to an increasing amount of ice in the column associated with the cloud thickness. The SW CRF, for times when the sun is above the horizon, has a weaker linear relationship with a shallower slope compared to the LW CRF. The average LW CRF of the thickest ice clouds $(6 \mathrm{~km})$ is still less than the LW CRF for optically thick liquid-bearing clouds. Thus, while ice properties can have important radiative effects, liquid properties dominate.

\section{Summary}

The radiative influence of clouds above Summit, Greenland, is investigated for the time period of January 2011-October 2013. Cloud radiative forcing, defined as the instantaneous radiative effect that clouds have in an atmospheric scene, is calculated by subtracting a modeled clear-sky radiative flux from the measured all-sky flux. Modeled fluxes are calculated using measured atmospheric thermodynamic profiles, estimated values for surface temperature and clear-sky albedo, and other parameters. Comparing modeled and measured fluxes during clear-sky scenes suggests that the CRF calculations could be biased by as much as $9.2 \mathrm{~W} \mathrm{~m}^{-2}$ as a result of not including aerosols in model calculations, differences in instrument viewing geometry, and other sources of model uncertainty. However, the bias in cloudy-sky CRF is expected to be smaller than this bias because aerosol forcing and field-of-view inconsistency biases are diminished under cloudy scenes.

Average monthly CRF values are positive year round, with an annual average of $33 \mathrm{~W} \mathrm{~m}^{-2}$. In addition, $98.5 \%$ of all quality-controlled 3-hourly data indicate that clouds above Summit Station act to warm the GIS. A cloud decreases the net amount of SW radiation at the surface when the sun is above the horizon, yet the magnitude of the cooling effect is limited by the high year-round surface albedo at Summit. Thus, the annual cycle of total CRF is dominated by the downwelling LW component. As a consequence of an increase in radiative flux at the surface, the net surface all-sky radiative flux is positive for a majority of the time in June and July and positive during $34 \%$ of the entire study period.

At Summit Station, because of a relatively constant cloud fraction $(\approx 86 \%)$ and cloud thickness throughout the year, the annual variability in liquid-bearing cloud properties largely drives the annual cycle of CRF. For LWP above $30 \mathrm{~g} \mathrm{~m}^{-2}$, a cloud becomes optically opaque to longwave radiation with a resultant LW surface warming of approximately $85 \mathrm{~W} \mathrm{~m}^{-2}$. The magnitude of the SW cooling effect only approaches the magnitude of the LW warming effect for large LWP and low SZA but 


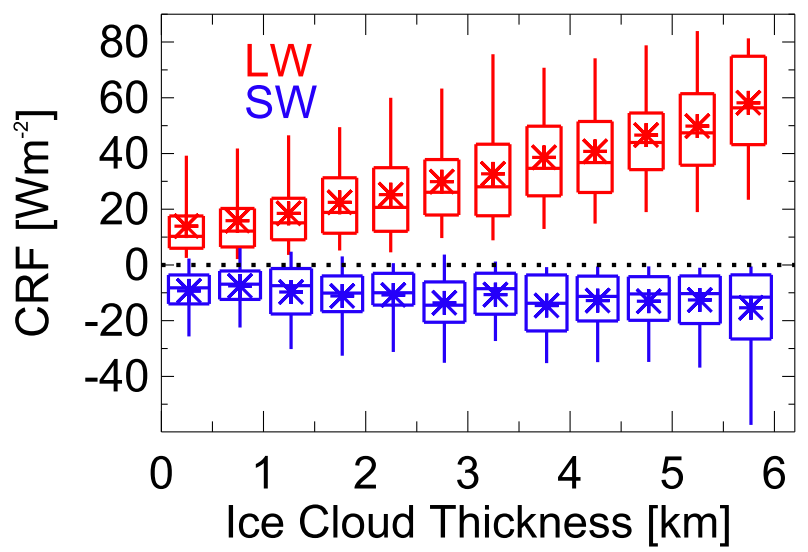

FIG. 10. Statistics of LW CRF (red) and SW CRF (blue) as a function of cloud physical thickness for clouds consisting of predominately of ice (LWP $<5 \mathrm{~g} \mathrm{~m}^{-2}$ ). The SW data are for SZA $<90^{\circ}$. The box indicates the 25 th and 75 th percentiles, the whiskers 5th and 95th percentiles, the horizontal line inside the box is the median, and the asterisk (*) indicates the mean.

generally SW cooling is smaller than the LW warming. For the smallest observed SZAs, the maximum surface warming is achieved under the influence of optically thin (LWP $=10-40 \mathrm{~g} \mathrm{~m}^{-2}$ ) liquid-bearing clouds. Interestingly, at Summit Station, the maximum warming due to clouds occurs in the late summer and early autumn due to a relatively constant surface albedo and marked increase from June to July in the LW warming effect of liquid-bearing clouds. This result is in contrast to other regions of the Arctic where the magnitude of SW cooling effect is larger than the LW warming effect for periods during the summer (Curry and Ebert 1992; Shupe and Intrieri 2004; Dong et al. 2010; Kay and L'Ecuyer 2013), leading to a minimum in the total CRF (maximum cooling) in July. The minimum CRF in central Greenland occurs in the spring, when there are a limited number of liquid-bearing clouds to warm the surface and the shortwave shading effect is a factor in lowering the total CRF at the surface.

Clouds consisting predominately of ice can also play an important role in warming the surface of the GIS. An increase in the integrated thickness of an ice cloud induces a response in the LW CRF that is greater in magnitude than the SW CRF. Hence, ice clouds warm the surface throughout the year, although they have a limited influence in the late summer when more liquid is present.

Cloud occurrence, liquid water path, and integrated ice cloud thickness all impact the atmospheric optical depth above the GIS, influencing the magnitude of warming at the surface. A change in the frequency of occurrence and/or microphysical properties of clouds over Summit will have implications for the net radiative flux at the surface and will enhance or temper the effects of a warming Arctic atmosphere. An increased (decreased) presence of clouds, especially those containing liquid water, would alter the current annual cycle of $\mathrm{CRF}$ at Summit by increasing (decreasing) warming of the surface. As the $0^{\circ} \mathrm{C}$ isotherm encroaches upon central Greenland in the next few decades, warming due to ubiquitous Arctic clouds will play an important role in determining the mass balance of the GIS.

Acknowledgments. This research is supported by the National Science Foundation under Grants PLR1303879, PLR1314156, PLR1314358, PLR1304692, and PLR1314248. Cox received support through the CIRES Visiting Fellows Program and the NOAA Climate Program Office. Thanks to the Swiss Federal Institute for providing the ETH broadband radiometer measurements. Additional broadband radiation measurements, ozonesonde soundings, $\mathrm{CO}_{2}$ measurements, and near-surface meteorological tower data are provided by the National Oceanic and Atmospheric Administration's Global Monitoring Division. The Department of Energy's Atmospheric Radiation Measurement Program provided the ceilometer and MPL measurements. Operational model output was obtained from Richard Forbes and the European Centre for Medium Range Weather Forecasts. The authors thank Polar Field Services and the various science technicians for their excellent support of the field experiments at Summit Station.

\section{REFERENCES}

Albrecht, B., and S. K. Cox, 1977: Procedures for improving pyrgeometer performance. J. Appl. Meteor., 16, 188-197, doi:10.1175/1520-0450(1977)016<0190:PFIPP>2.0.CO;2.

Bennartz, R., and Coauthors, 2013: July 2012 Greenland melt extent enhanced by low-level liquid clouds. Nature, 496, 83-86, doi:10.1038/nature12002.

Bourgeois, C. S., 2006: The radiative properties of snow at Summit, Greenland. Ph.D. thesis, Swiss Federal Institute of Technology (ETH), 108 pp.

Box, J. E., X. Fettweis, J. C. Stroeve, M. Tedesco, D. K. Hall, and K. Steffen, 2012: Greenland ice sheet albedo feedback: Thermodynamics and atmospheric drivers. Cryosphere, 6, 821-839, doi:10.5194/tc-6-821-2012.

Cesana, G., J. E. Kay, H. Chepfer, J. M. English, and G. de Boer, 2012: Ubiquitous low-level liquid-containing Arctic clouds: New observations and climate model constraints from CALIPSO-GOCCP. Geophys. Res. Lett., 39, L20804, doi:10.1029/2012GL053385.

Clough, S., M. Shephard, E. Mlawer, J. Delamere, M. Iacono, K. Cady-Pereira, S. Boukabara, and P. Brown, 2005: Atmospheric radiative transfer modeling: A summary of the AER codes. J. Quant. Spectrosc. Radiat. Transfer, 91, 233-244, doi:10.1016/j.jqsrt.2004.05.058.

Cox, C. J., V. P. Walden, G. Compo, P. Rowe, M. D. Shupe, and K. Steffen, 2014: Downwelling longwave flux over Summit, Greenland, 2010-2012: Analysis of surface-based observations 
and evaluation of ERA-Interim using wavelets. J. Geophys. Res., 119, 12317-12 337, doi:10.1002/2014JD021975.

Crewell, S., and U. Löhnert, 2003: Accuracy of cloud liquid water path from ground-based microwave radiometry 2. Sensor accuracy and synergy. Radio Sci., 38, 8042, doi:10.1029/ 2002RS002634.

Cullen, N. J., and K. Steffen, 2001: Unstable near-surface boundary conditions in summer on top of the Greenland ice sheet. Geophys. Res. Lett., 28, 4491-4493, doi:10.1029/2001GL013417.

Curry, J. A., and G. F. Herman, 1985: Infrared radiative properties of summertime Arctic stratus clouds. J. Climate Appl. Meteor., 24, 525-538, doi:10.1175/1520-0450(1985)024<0525: IRPOSA $>2.0 . \mathrm{CO} ; 2$.

— , and E. E. Ebert, 1992: Annual cycle of radiation fluxes over the Arctic Ocean: Sensitivity to cloud optical properties. J. Climate, 5, 1267-1280, doi:10.1175/1520-0442(1992) 005<1267:ACORFO > 2.0.CO;2.

—, F. G. Meyer, L. F. Radke, C. A. Brock, and E. E. Ebert, 1990: Occurrence and characteristics of lower tropospheric ice crystals in the Arctic. Int. J. Climatol., 10, 749-764, doi:10.1002/joc.3370100708.

de Boer, G., W. D. Collins, S. Menon, and C. N. Long, 2011: Using surface remote sensors to derive radiative characteristics of mixed-phase clouds: An example from M-PACE. Atmos. Chem. Phys., 11, 11 937-11 949, doi:10.5194/acp-11-11937-2011.

Dlugokencky, E. J., P. Lang, K. Masarie, A. Crotwell, and M. Crotwell, 2014: Atmospheric carbon dioxide dry air mole fractions from the NOAA ESRL Carbon Cycle Cooperative Global Air Sampling Network, 1968-2013 (version: 2014-06-27). NOAA/ESRL. [Available online at ftp://aftp.cmdl.noaa.gov/ data/trace_gases/co2/flask/surface/.]

Dong, X., B. Xi, K. Crosby, C. N. Long, R. S. Stone, and M. D. Shupe, 2010: A 10 year climatology of Arctic cloud fraction and radiative forcing at Barrow, Alaska. J. Geophys. Res., 115, D17212, doi:10.1029/2009JD013489.

Fitzpatrick, M. F., and S. G. Warren, 2005: Transmission of solar radiation by clouds over snow and ice surfaces. Part II: Cloud optical depth and shortwave radiative forcing from pyranometer measurements in the Southern Ocean. J. Climate, 18, 4637-4648, doi:10.1175/JCLI3562.1.

Grenfell, T. C., D. K. Perovich, and J. A. Ogren, 1981: Spectral albedos of an alpine snowpack. Cold Reg. Sci. Technol., 4, 121127, doi:10.1016/0165-232X(81)90016-1.

Gröbner, J., I. Reda, S. Wacker, S. Nyeki, K. Behrens, and J. Gorman, 2014: A new absolute reference for atmospheric longwave irradiance measurements with traceability to SI units. J. Geophys. Res. Atmos., 119, 7083-7090, doi:10.1002/2014JD021630.

Henderson-Sellers, A., and K. McGuffie, 1990: Basis for integration of conventional observations of cloud into global nephanalyses. J. Atmos. Chem., 11, 1-25, doi:10.1007/BF00053665.

Intrieri, J. M., C. W. Fairall, M. D. Shupe, P. O. G. Persson, E. L Andreas, P. S. Guest, and R. E. Moritz, 2002: An annual cycle of Arctic surface cloud forcing at SHEBA. J. Geophys. Res., 107, 8039, doi:10.1029/2000JC000439.

Kato, S., T. P. Ackerman, E. E. Clothiaux, J. H. Mather, G. G. Mace, M. L. Wesely, F. Murcray, and J. Michalsksy, 1997: Uncertainties in modeled and measured clear-sky surface shortwave irradiances. J. Geophys. Res., 102, 25 881-25 898, doi:10.1029/97JD01841.

Kay, J. E., and T. L'Ecuyer, 2013: Observational constraints on Arctic Ocean clouds and radiative fluxes during the early $21 \mathrm{st}$ century. J. Geophys. Res., 118, 7219-7236, doi:10.1002/ jgrd.50489.
Kuipers Munneke, P., M. R. van den Broeke, C. H. Reijmer, M. M. Helsen, W. Boot, M. Schneebeli, and K. Steffen, 2009: The role of radiation penetration in the energy budget of the snowpack at Summit, Greenland. Cryosphere, 3, 155-165, doi:10.5194/tc-3-155-2009.

Long, C. N., and T. P. Ackerman, 2000: Identification of clear skies from broadband pyranometer measurements and calculation of downwelling shortwave cloud effects. J. Geophys. Res., 105, 15 609-15 626, doi:10.1029/2000JD900077.

— and D. D. Turner, 2008: A method for continuous estimation of clear-sky downwelling longwave radiative flux developed using ARM surface measurements. J. Geophys. Res., 113, D18206, doi:10.1029/2008JD009936.

McClatchey, R. A., R. W. Fenn, J. E. A. Selby, F. E. Volz, and J. S. Garing, 1972: Optical properties of the atmosphere. Rep. AFCRL-72-0497, Hanscom Air Force Base, Bedford, MA, $110 \mathrm{pp}$.

McGrath, D., D. W. Colgan, N. Bayou, A. Muto, and K. Steffen, 2013: Recent warming at Summit, Greenland: Global context and implications. Geophys. Res. Lett., 40, 2091-2096, doi:10.1002/grl.50456.

Mernild, S. H., T. L. Mote, and G. E. Liston, 2011: Greenland ice sheet surface melt extent and trends: 1960-2010. J. Glaciol., 57, 621-628, doi:10.3189/002214311797409712.

Miller, N. B., D. D. Turner, R. Bennartz, M. D. Shupe, M. S. Kulie, M. Cadeddu, and V. P. Walden, 2013: Surface-based inversions above central Greenland. J. Geophys. Res., 118, 495506, doi:10.1029/2012JD018867.

Mlawer, E. J., V. H. Payne, J.-L. Moncet, J. S. Delamere, M. J. Alvarado, and D. C. Tobin, 2012: Development and recent evaluation of the MT_CKD model of continuum absorption. Philos. Trans. Roy. Soc. London, 370A, 2520-2556, doi:10.1098/rsta.2011.0295.

Nghiem, S. V., and Coauthors, 2012: The extreme melt across the Greenland ice sheet in 2012. Geophys. Res. Lett., 39, L20502, doi:10.1029/2012GL053611.

Petty, G. W., 2006: A First Course in Atmospheric Radiation. Sundog Publishing, 459 pp.

Ramanathan, V., R. D. Cess, E. F. Harrison, P. Minnis, B. R. Barkstrom, E. Ahmad, and D. Hartmann, 1989: Cloudradiative forcing and climate: Results from the Earth $\mathrm{Ra}$ diation Budget Experiment. Science, 243, 57-63, doi:10.1126/ science.243.4887.57.

Sedlar, J., and Coauthors, 2011: A transitioning Arctic surface energy budget: The impacts of solar zenith angle, surface albedo and cloud radiative forcing. Climate Dyn., 37, 1643-1660, doi:10.1007/s00382-010-0937-5.

Shupe, M. D., and J. M. Intrieri, 2004: Cloud radiative forcing of the Arctic surface: The influence of cloud properties, surface albedo, and solar zenith angle. J. Climate, 17, 616-628, doi:10.1175/1520-0442(2004)017<0616:CRFOTA >2.0.CO;2.

, V. P. Walden, E. Eloranta, T. Uttal, J. R. Campbell, S. M. Starkweather, and M. Shiobara, 2011: Clouds at Arctic atmospheric observatories. Part I: Occurrence and macrophysical properties. J. Appl. Meteor. Climatol., 50, 626-644, doi:10.1175/2010JAMC2467.1.

_, and Coauthors, 2013: High and dry: New observations of tropospheric and cloud properties above the Greenland ice sheet. Bull. Amer. Meteor. Soc., 94, 169-186, doi:10.1175/ BAMS-D-11-00249.1.

Stamnes, K., R. G. Ellingson, J. A. Curry, J. E. Walsh, and B. D. Zak, 1999: Review of science issues, deployment strategy, and status for the ARM North Slope of Alaska-Adjacent Arctic 
Ocean climate research site. J. Climate, 12, 46-63, doi:10.1175/ 1520-0442-12.1.46.

Su, W., E. Dutton, T. P. Charlock, and W. Wiscombe, 2008: Performance of commercial radiometers in very low temperature and pressure environments typical of polar regions and of the stratosphere: A laboratory study. J. Atmos. Oceanic Technol., 25, 558-569, doi:10.1175/2007JTECHA1005.1.

Turner, D. D., and E. J. Mlawer, 2010: The radiative heating in underexplored bands campaigns. Bull. Amer. Meteor. Soc., 91, 911-923, doi:10.1175/2010BAMS2904.1.

—, B. M. Lesht, S. A. Clough, J. C. Liljegren, H. E. Revercomb, and D. C. Tobin, 2003: Dry bias and variability in Vaisala RS80-H radiosondes: The ARM experience. J. Atmos. Oceanic Technol., 20, 117-132, doi:10.1175/1520-0426(2003)020<0117: DBAVIV $>2.0 . \mathrm{CO} ; 2$.

, S. A. Clough, J. C. Liljegren, E. E. Clothiaux, K. E. CadyPereira, and K. L. Gaustad, 2007: Retrieving liquid water path and precipitable water vapor from the Atmospheric
Radiation Measurement (ARM) microwave radiometers. IEEE Trans. Geosci. Remote Sens., 45, 3680-3690, doi:10.1109/ TGRS.2007.903703.

Vuilleumier, L., M. Hauser, C. Flix, F. Vignola, P. Blanc, A. Kazantzidis, and B. Calpini, 2014: Accuracy of ground surface broadband shortwave radiation monitoring. $J$. Geophys. Res. Atmos., 119, 13838-13860, doi:10.1002/ 2014JD022335.

Walsh, J. E., and W. L. Chapman, 1998: Arctic cloud radiation temperature associations in observational data and atmospheric reanalyses. J. Climate, 11, 3030-3045, doi:10.1175/ 1520-0442(1998)011<3030:ACRTAI>2.0.CO;2.

Warren, S. G., 1982: Optical properties of snow. Rev. Geophys. Space Phys., 20, 67-89, doi:10.1029/RG020i001p00067.

Zwally, H. J., W. Abdalati, T. Herring, K. Larson, J. Saba, and K. Steffen, 2002: Surface melt-induced acceleration of Greenland ice-sheet flow. Science, 297, 218-222, doi:10.1126/ science. 1072708 . 